И.И. МАЦКО, асп., ФГБОУ ВПО "МГТУ им. Г.И. Носова", Магнитогорск,

О.С. ЛОГУНОВ $\boldsymbol{A}$, д-р. техн. наук, проф., ФГБОУ ВПО "МГТУ им. Г.И. Носова", Магнитогорск

\title{
ИНТЕГРАЦИЯ ЭРГАТИЧЕСКОГО МОДУЛЯ ОЦЕНКИ КАЧЕСТВА НЕПРЕРЫВНО-ЛИТОЙ ЗАГОТОВКИ В АСУ ТП МЕТАЛЛУРГИЧЕСКОГО ПРОИЗВОДСТВА ${ }^{1}$
}

Представлена схема интеграции эргатического модуля оценки качества непрерывнолитой заготовки в АСУ ТП металлургического производства с учетом последовательности получения и обработки стали, а также системы принятия решений о состоянии технологической цепочки на основе этой оценки. Ил.: 1. Библиограф.: 9 назв.

Ключевые слова: эргатический модуль оценки качества, схема интеграции, система принятия решения, технологическая цепочка, металлургическое производство.

Постановка проблемы и анализ литературы. Все современные металлургические предприятия применяют автоматизированные системы управления технологическими процессами (АСУ ТП) и в большинстве случаев выполняется независимое управление отдельными цепочками полного цикла производства. Использование каскадного управления технологическими цепочками, является одним из комплексных подходов к АСУ ТП, позволяющим управлять внешними воздействиями, передающимися с предыдущих технологических этапов производства.

Существует устойчивое мнение о том, что макроструктура стали формируется только под воздействием факторов, действующих на непрерывно-литую заготовку (НЛЗ) в процессе ее охлаждения на машине непрерывного литья заготовок (МНЛЗ). Учитывая, что производство заготовки выполняется серийно и каждая серия может содержать до 50 плавок, существует возможность корректировки технологии не только на участке непрерывной разливки, но и на предыдущих этапах.

В настоящее время оценка макроструктуры непрерывно-литых заготовок на ОАО "Магнитогорский металлургический комбинат" (ОАО "ММК") производится на основе стандартов и технологических инструкций [1] и [2]. Изучение описательных характеристик и областей расположения внутренних макродефектов непрерывно-литой заготовки позволило выполнить математическое описание каждого вида дефекта [3,

\footnotetext{
1 Научные исследования выполняются при финансовой поддержке грантов Правительства Челябинской области и ФГБОУ ВПО "Магнитогорский государственный технический университет им. Г.И. Носова"
} 
4], спроектировать и разработать программный модуль для оценки качества непрерывно-литой заготовки в автоматизированном режиме [5].

Цель работы - интеграция в АСУ ТП эргатического модуля автоматизированной оценки качества непрерывно-литой заготовки с учетом каскадного управления технологическими цепочками.

Схема интеграции в АСУ ТП программного модуля автоматизированной оценки качества непрерывно-литой заготовки.

Учитывая технологические инструкции и стандарты на

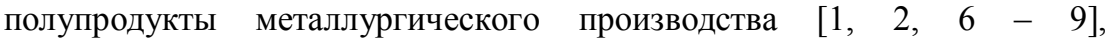
применяемые на ОАО "ММК" была разработана схема интеграции (рис.) программного модуля в АСУ ТП технологической цепочки производства непрерывно-литой заготовки в условиях ЭСПЦ ОАО "ММК". В каскадной схеме управления используется три блока: 1 - контур управления выплавкой стали в дуговых электросталеплавильных печах (ДСП); 2 - контур управления обработкой металла на установке печьковш (УПК); 3 - контур управления непрерывной разливкой стали на машинах непрерывного литья заготовок (МНЛЗ).

На рис. введены обозначения: $Z_{1}^{1}$ - задание УПК на соотношение массы шихтовых материалов; $Z_{1}^{2}-$ задание УПК на габаритные размеры металлолома; $Z_{2}^{1}$ - температура металла после выпуска; $\left\{Z_{2}^{2}\right\}$ - значение процентного содержания химических элементов марочного содержания после выпуска; $Z_{3}^{1}$ - температура металла после доводки; $\left\{Z_{3}^{2}\right\}$ значение процентного содержания химических элементов марочного содержания после доводки; $Z_{1}^{K 1}$ - скорректированное задание дуговой сталеплавильной печи на соотношение массы шихтовых материалов; $Z_{1}^{K 2}$ - скорректированное задание ДСП на габаритные размеры металлолома; $Z_{2}^{K 1}$ - скорректированное задание установке печь-ковш (УПК) по конечной температуре металла; $Z_{2}^{K 2}-$ скорректированное задание УПК на процентное содержание химических элементов марочного содержания; $Z_{3}^{K 1}$ - скорректированное задание МНЛЗ на расход охладителя в зонах вторичного охлаждения; $Z_{3}^{K 2}$ скорректированное задание МНЛЗ на регулирование состава и расхода шлакообразующей смеси (ШОС) в кристаллизаторе МНЛ3; $\left\{Z_{1}^{6 x}\right\}$ расчетные значения режимов локальных контуров управления ДСП (электрический режим, расход ШОС, расход ферросплавов, расход 
инертных газов, температурный режим); $\left\{Z_{2}^{6 x}\right\}$ - расчетные значения режимов локальных контуров управления УПК (электрический режим, расход ШОС, расход ферросплавов, расход инертных газов, температурный режим, расход раскисляющих и легирующих материалов); $\left\{Z_{3}^{6 x}\right\}$ - расчетные значения режимов локальных контуров управления МНЛЗ (расход воды, скорость вытягивания, расход ШОС, амплитуда и частота качания кристаллизатора); $V_{\text {выx }}$ - объем выхода годной заготовки; $I_{3}$ - образец, в виде темплета и (или) его серного отпечатка; $\left\{O_{\ni}\right\}$ - экспертные оценки макродефектов на поверхности темплета по классам ОСТ 14-4-73 [2]; $K_{1}$ - указание на корректировку управления ДСП; $K_{2}$ - указание на корректировку управления УПК; $K_{3}$ - указание на корректировку управления МНЛз; $\left\{Z_{1}^{p}\right\}$ - значения промоделированных параметров локальных контуров управления ДСП; $\left\{Z_{2}^{p}\right\}$ - значения промоделированных параметров локальных контуров управления УПК; $\left\{Z_{3}^{p}\right\}$ - значения промоделированных параметров локальных контуров управления МНЛЗ; $\Delta Z_{1}^{1}-$ коррекция задания ДСП на соотношение массы шихтовых материалов; $\Delta Z_{1}^{2}-$ коррекция задания ДСП на габаритные размеры металлолома; $\Delta Z_{2}^{1}-$ коррекция задания УПК на температуру металла; $\Delta Z_{2}^{2}-$ коррекция задания УПК на процентное содержание химических элементов марочного содержания; $\Delta Z_{3}^{1}$ - коррекция задания УПК на охлаждение сляба; $\Delta Z_{3}^{2}-$ коррекция задания УПК на процентное содержание химических элементов в назначаемой марке стали.

В глобальных контурах $(1,2,3)$ блок моделей процессов принимает указания на корректировку параметров технологии. С учетом указаний смоделированные параметры передаются блоку принятия решений о корректировке входных параметров. После внесения корректировок во входные данные локальные контуры выбирают значения управляемых параметров, которыми воздействуют на управляемый объект. В глобальных контурах ДСП и УПК $(1,2)$ управляемыми объектами является жидкий металл, в МНЛЗ (3) - заготовка. В глобальном контуре управления непрерывной разливкой стали значения управляемых параметров обладают инерционностью, определенной протяженностью МНЛЗ и конструкцией зон вторичного охлаждения. 


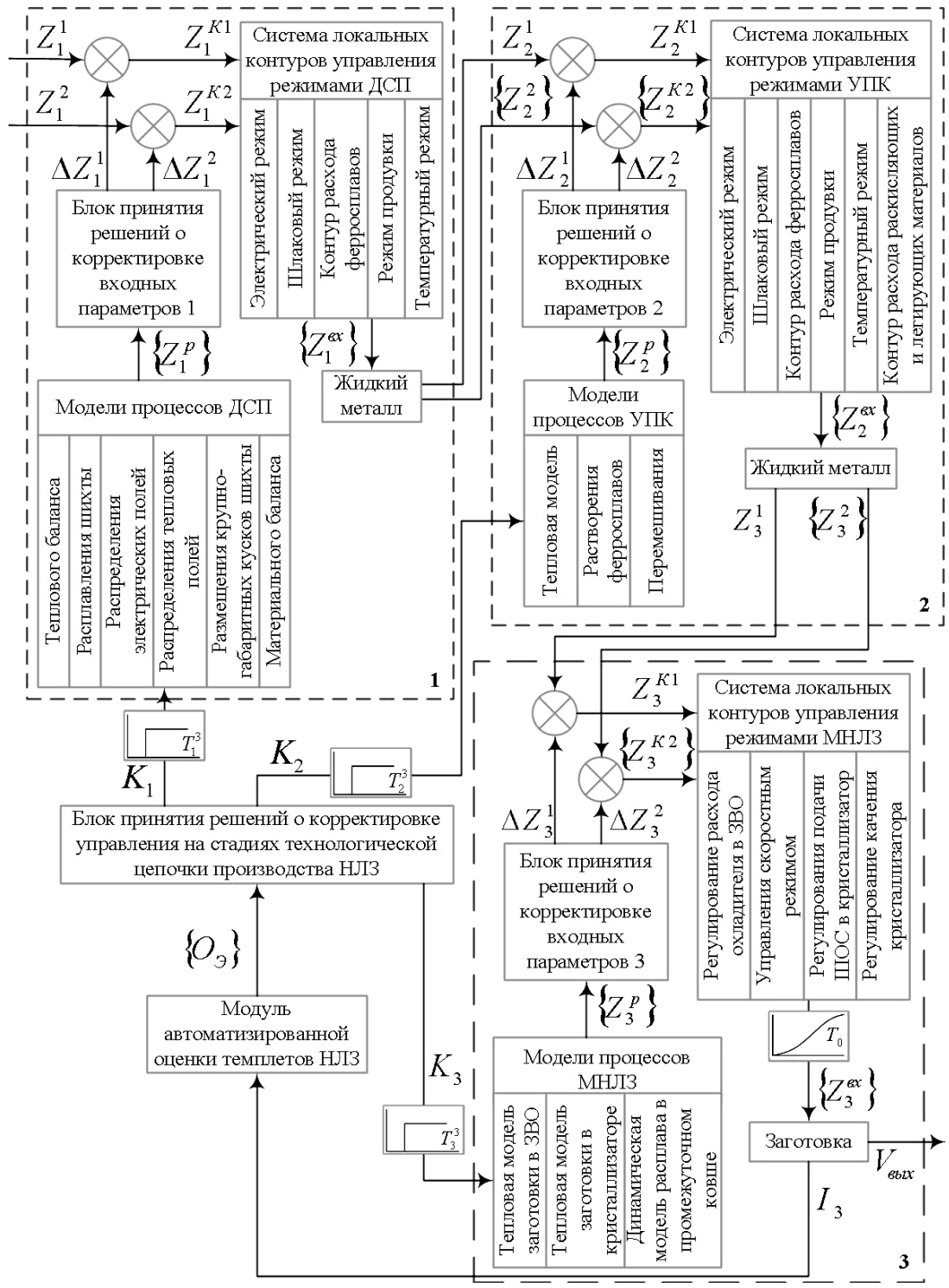

Рис. Схема интеграции в АСУ ТП программного модуля автоматизированной оценки качества непрерывно-литой заготовки 
Образец, в виде темплета и (или) его серного отпечатка поступает в модуль автоматизированной оценки темплетов НЛЗ. После обработки поступившего изображения модуль передает экспертные оценки макродефектов на поверхности темплета блоку принятия решений о корректировке управления на стадиях технологической цепочки производства НЛЗ.

Блок принятия решения формирует указания на корректировку управления, которые передаются с запаздыванием в блоки математических моделей процессов глобальных контуров для расчета физических значений управляемых параметров. Принятое решение передается в каждую подсистему глобального контура с запаздыванием, которое возникает в результате временных интервалов, необходимых для выполнения операций на последующие стадии обработки жидкого металла, заготовки или образца. Каждая система содержит несколько локальных контуров, способных управлять одним параметром по указанному заданию. В настоящее время предлагается множество математических моделей, позволяющих вычислять и оптимизировать параметры управления на каждом этапе технологической цепочки. Эти математические модели составляют основу математического обеспечения глобального и системы локальных контуров управления.

Выводы. В работе доказано, что существует возможность корректировки серийной технологии на всех этапах производства непрерывно-литой заготовки. Каскадное управление позволяет контролировать внешние воздействия, передающиеся с предыдущих технологических этапов производства и извне. В работе представлен один из вариантов интеграции в АСУ ТП металлургического производства эргатического модуля автоматизированной оценки качества непрерывно-литой заготовки, обеспечивающего информационную и программную поддержку обратной связи в системе каскадного управления технологической цепочкой получения готовой продукции.

Список литературы: 1. Технологическая инструкция ТИ 101-Я-7-2009. Контроль макроструктуры непрерывнолитых слябов производства ОАО "ММК". Отбор, механическая обработка, снятие серных отпечатков и травление темплетов. - Магнитогорск: ОАО "ММК", 2009. - 13 с. 2. Отраслевой стандарт ОСТ 14-4-73. Сталь. Метод контроля макроструктуры литой заготовки (слитка), полученной методом непрерывной разливки, введ. 1973.07.01. - М.: Министерство черной металлургии СССР, 1973. - 15 с. 3. Мацко И.И. Математическое обеспечение распознавания объектов нерегулярной формы на цветных изображениях темплетов / И.И. Мацко, О.С. Логунова // Информационные технологии в проектировании и производстве. - 2011. - № 3. - С. 87-92. 4. Логунова О.С. Комплексная подсистема управления на металлургическом предприятии / О.С. Логунова, И.И. Мачко, B.B. Павлов // Проблемы теории и практики управления. - 2011. - № 9. - С. 51-58. 5. Логунова O.C. Алгоритмы и программное обеспечение распознавания низко-контрастных 
изображений при оценке качества стали / О.С. Логунова, П.П. Макарычев // Программные продукты и системы. - 2008. - № 3. - С. 79-81. 6. Технологическая инструкция ТИ 101-СТЭСПЦ-64-2007. Выплавка стали в электропечах. - Магнитогорск: ОАО "ММК", 2007. 43 с. 7. Технологическая инструкция ТИ 101-СТ-ККЦ-22-2005. Обработка металла на агрегате доводки стали и установке усреднительной продувки металла в ковше. Магнитогорск: ОАО "ММК", 2005. - 26 с. 8. Технологическая инструкция ТИ 101-СТ-ККЦ83-2008. Обработка стали на установке печь-ковш. - Магнитогорск: ОАО "ММК", 2008. 24 с. 9. Технологическая инструкция ТИ 101-СТ-ККЦ-96-2010. Разливка стали на одноручьевой машине непрерывного литья заготовок № 6 (МНЛ3 № 6) кислородноконвертерного цеха. - Магнитогорск: ОАО "ММК", 2010. - 86 с.

Статью представил д.т.н., проректор по научной работе ФГБОУ ВПО "Магнитогорский государственный технический университет им. Г.И. Носова", проф. Вдовин К.Н.

\section{УДК 621.746.047:004.42}

Інтеграція ергатичних модуля оцінки якості безперервно-литої заготовки в АСУ ТП металургійного виробництва / Мацко І.І., Логунова О.С. // Вісник НТУ "ХПІ". Серія: Інформатика та моделювання. - Харків: НТУ "ХПІ". - 2012. - №. 38. - С. 115 - 120.

Представлена схема інтеграції ергатичних модуля оцінки якості безперервно-литої заготовки в АСУ ТП металургійного виробництва з урахуванням послідовності отримання та обробки сталі, а також системи прийняття рішень про стан технологічного ланцюжка на основі цієї оцінки. Іл.: 1. Бібліогр.: 9 назв.

Ключові слова: ергатичний модуль оцінки якості, схема інтеграції, система прийняття рішення, технологічний ланцюжок, металургійне виробництво.

UDC 621.746.047:004.42

Integration of quality estimation ergatic module into metallurgical enterprise PCS // Matsko I.I., Logunova O.S. // Herald of the National Technical University "KhPI". Subject issue: Information Science and Modelling. - Kharkov: NTU "KhPI". - 2012. - №.. - P. 115 - 120.

The article represents the scheme of integration of quality estimation ergatic module into metallurgical enterprise PCS taking steel aquisition and processing into account. Decision making system, based on that estimation, is also represented. Figs: 1. Refs: 9 titles.

Keywords: quality estimation ergatic module, integration scheme, decision making system, technological chain, metallurgical enterprise.

Поступила в редакцию 03.04.2012 